\title{
“LIBERTÉ, ÉGALITÉ, BEYONCÉ"1: O FEMINISMO EM MÚSICAS POP INTERNACIONAL ${ }^{2}$
}

\author{
"LIBERTÉ, ÉGALITÉ, BEYONCÉ": FEMINISM IN INTERNATIONAL POP MUSIC
}

\section{RESUMO}

Propomos discutir criticamente a presença de contextos e propostas feministas nas letras de músicas pop internacional das cantoras Ariana Grande, Marina \& the Diamonds, Dua Lipa, principalmente em músicas da cantora Beyoncé, abarcando questões sobre feminismos e feminismo negro.

Palavras-chave: Feminismo negro. Estudos de gênero. Músicas feministas.

\begin{abstract}
We propose to discuss, critically, the presence of feminist contexts in international pop music lyrics of singers Ariana Grande, Marina \& the Diamonds, Dua Lipa, especially Beyoncé's songs, involving issues of feminism and black feminism.
\end{abstract}

Keywords: Black feminism. Gender studies. Feminist songs.

1 Paródia de liberté, égalité, fraternité (liberdade, igualdade, fraternidade), lema da Revolução Francesa, do século XVIII, que inaugurou o estado de direito francês, posteriormente, passando a constar da própria constituição do país e do seu governo republicano. Esta paródia se tornou comum entre comunidades gays da internet após a circulação da foto de um muro parisiense pichado que substituía o tradicional fraternité pelo nome da cantora estadunidense Beyoncé.

2 O presente trabalho foi realizado com apoio da Coordenação de Aperfeiçoamento de Pessoal de Nível Superior (CAPES - código de financiamento oo1). Grupos de pesquisa de vínculo (CNPq): 1) Estudos em Línguas e Literaturas Estrangeiras; 2) Literatura, história e cultura: encruzilhadas epistemológicas; 3) A narrativa de nação e o feminino.

Renato Gonçalves Peruzzo

Doutorando (e Mestre) em Letras: Linguagens e Representações - Universidade Estadual de Santa Cruz (UESC), Ilhéus, BA, Brasil. E-mail: naticos15@gmail.com

\section{Sandra Sacramento}

Professora Plena da Universidade Estadual de Santa Cruz (UESC), Ilhéus, BA, Brasil. Doutora em Letras (UFRJ). E-mail: sandramsacramento@hotmail.com 
Mode on high tech

Modelo ocidental

Magra, clara e alta

Miss beleza universal

É ditadura!

Quanta opressão

Não basta ser mulher

Tem que tá dentro do padrão

Miss beleza, miss beleza universal Miss beleza, miss beleza universal Miss beleza, miss beleza universal Miss beleza, miss beleza universal

(“Miss beleza universal”, Doralyce)

No presente artigo, propomos discutir criticamente a presença de contextos e propostas feministas nas letras das músicas da cantora internacional de pop estadunidense Beyoncé. É necessário acrescentar, a este ponto, que a pesquisa se ateve às letras de suas músicas, desconsiderando outros aspectos, por exemplo, melodias, materiais visuais de divulgação e videoclipes.

$\mathrm{O}$ artigo está dividido em duas seções principais e considerações finais: na primeira seção, serão discutidas questões sobre feminismos e feminismo negro, bem como contextos feministas em letras de músicas de pop internacional; na segunda seção, será feita a análise de letras de músicas de Beyoncé que contenham cunho feminista. Por fim, as considerações finais.

\section{Estranhamentos feministas}

Desde a luta pelo sufrágio universal, perpassando às discussões de público e privado, até às discussões acerca dos gêneros, do aborto, da posse de si e do corpo, entre outras questões, o feminismo tem sido julgado, principalmente desde as últimas décadas do século XX, por representar, política e simbolicamente, apenas o chamado "universal" - com cor e classe social -, deixando de lado aquelas mulheres que estiveram historicamente à margem dos debates.

É a partir do final da "segunda onda" e da vivência da "terceira onda" que questões interseccionais (raça, classe etc.) passaram a ser incorporadas às suas linhas de força (AMORÓS; ÁLVAREZ, 2010; PULEO, 2010; SCHMIDT, 2017; SCOTT, 2002); inclusive, gerando novos movimentos feministas, a exemplo do putafeminismo (MOIRA, 2016; PRADA, 2018) e do transfeminismo (JESUS, 2013). Daí a utilização mais adequada de "feminismos", no plural - diferente da visão anterior, que homogeneizava causas e pessoas. 
A necessidade de um feminismo negro acontece sobretudo por causa do entendimento de que os corpos femininos, ditos frágeis e delicados, jamais se referiram aos corpos negros: enquanto as mulheres brancas - participantes do universal - eram narradas como mulheres para o lar, para o cuidado materno, para a família, as mulheres negras estiveram sujeitadas à escravidão, ao silenciamento e às margens da sociedade, servindo, inclusive, àquelas famílias brancas.

Em relação às famílias, a socióloga nigeriana Oyèrónké Oyěwùmí (2000; 2004) defende que o feminismo ocidental pensa seus conceitos a partir de uma perspectiva familiar nuclear, branca e patriarcal, generificada desde sua constituição:

I wish to suggest that feminist concepts are rooted in the nuclear family. This social institution constitutes the very basis of feminist theory and represents the vehicle for the articulation of feminist values. [...] Despite the fact that feminism has gone global, it is the Western nuclear family that provides the grounding for much of feminist theory. Thus the three central concepts that have been the mainstay of feminism woman, gender, and sisterhood are only intelligible with careful attention to the nuclear family from which they emerged. (OYĚWÙMÍ, 2004, p. 2). ${ }^{3}$

A crítica fundada pela autora ao feminismo ocidental é a de que seus conceitos se articulam com a formação familiar europeia, formada pelo marido que sustenta a família e pela esposa que organiza e prioriza as tarefas do lar, além de cuidar e educar os filhos do casal, tendo esse modelo familiar como base. Dessa forma, a mulher seria pensada apenas, ou primeiramente, a partir de sua função familiar (esposa/mãe).

Assim, outras formações familiares, como a família iorubá pré-colonização, que determinavam os papeis familiares por antiguidade (maior idade), constituindose como alternativa de família não-generificada. Segundo a escritora, o feminismo ocidental, por estar preso no modelo familiar branco, não considera outras interseccionalidades e variáveis, como as questões de raça e classe social.

Nessa esfera do social, o feminismo negro se fez (e ainda se faz) necessário, pois apenas um feminismo diferente, que perceba esses outros corpos, permite compreender e responder ativamente às implicações das interseccionalidades entre categorias distintas, mas igualmente subordinadas: ser mulher e ser negra.

Como a filósofa Simone de Beauvoir (2016a; 2016b) já eternizou no título de sua obra O segundo sexo, a mulher sempre esteve para o segundo dos pares (homem/ mulher, rico/pobre, dominador/dominado, colonizador/colonizado etc.); ou seja, para o outro - nesse caso, do sexo. A autora Djamila Ribeiro (2017), ao propor sua discussão

3 "Desejo sugerir que os conceitos feministas são enraizados na família nuclear. Essa instituição social constitui a própria base da teoria feminista e representa o veículo de articulação dos valores feministas. [...] Apesar do fato de o feminismo ter se tornado global, é a família nuclear ocidental que provém o fundamento para maioria da teoria feminista. Assim, os três conceitos centrais pilares do feminismo: mulher, gênero e sororidade são apenas compreensíveis com cuidadosa atenção ao modelo familiar nuclear de onde emergiram" (OYĚWÙMÍ, 2004, p. 2, tradução nossa). 
principalmente a partir da feminista Grada Kilomba, acrescenta que a mulher negra experimenta dois processos de subordinação social, tornando-se "o outro do outro".

Além da questão mais basilar do feminismo de resistir à subordinação imposta pelo patriarcado, que desvaloriza a mulher ao passo que supervaloriza o homem, as mulheres negras ainda convivem com o estigma histórico. A comunidade negra foi, por longos anos, escravizada e a mulher negra teve papel fundamental no processo, dado que eram elas as reprodutoras.

Aliás, após a Abolição da Escravatura, no Brasil, em 1888, que ocorre na lei e não no âmbito social, permanece o racismo e a humilhação. Espera-se que as mulheres negras assumam apenas espaços similares aos da escravidão, principalmente, os hierarquicamente marcados e de possível humilhação, como serviçais, domésticas, prostitutas.

Se, por um lado, temos o racismo, por outro, temos a hipersexualização dos corpos negros: homens e mulheres negros são fetichizados socialmente, sendo vistos como lascivos e libidinosos. Pensa-se que o corpo da mulher negra tem a missão de satisfazer os superiores - quer seja nos serviços anteriores, quer seja no âmbito sexual.

Nesse contexto de abjeção, de subalternidade e de invisibilização, a mulher negra está marcadamente abaixo dos homens e dos brancos. Esse processo de dupla alteridade se dá por conta de a mulher negra ser ora o outro do homem, ora o outro do branco. Dessa forma, teríamos uma espécie de pirâmide que prevê o homem sempre acima da mulher, mas os brancos sempre acima dos negros, conforme segue:

Figura 1 - Hierarquia "o outro do outro"

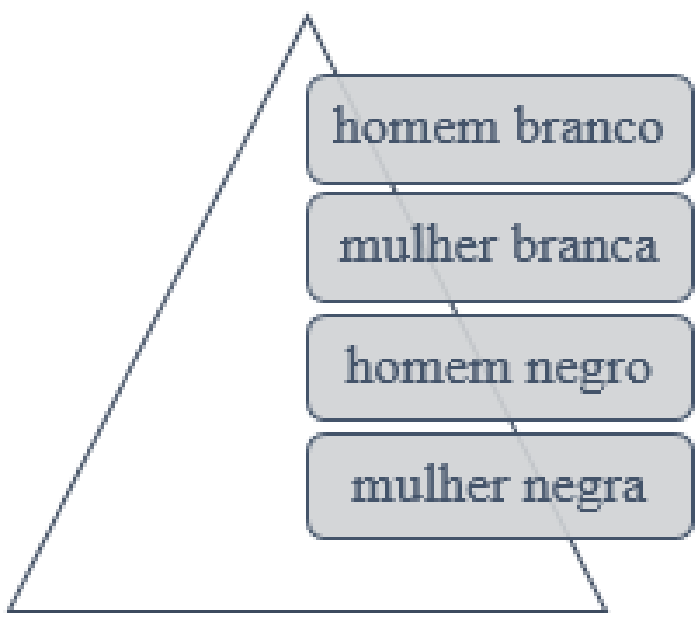

Fonte: Elaborada pelxs autorxs do artigo a partir de Ribeiro (2017).

A figura anterior, elaborada a partir das conclusões de Djamila Ribeiro, que retoma as discussões das feministas bell hooks, Gadra Kilomba e Patricia Hill Collins, apresenta as opressões sofridas pela mulher negra que sustenta a base das relações estabelecidas entre homens e mulheres brancas, bem como destes com os homens 
negros. Portanto, as mulheres negras são exploradas por todos os outros indivíduos da hierarquia supracitada.

Nesse contexto, é que se torna necessário compreender que as mulheres negras, por conta de serem duplamente subalternizadas (FERNANDES, 2016; RIBEIRO, 2017; SPIVAK, 1994), buscam construir outros feminismos. Novas linhas de feminismos, que discutam e promovam soluções mais pontuais acerca de questões como o encarceramento da população negra, a morte dos jovens negros, a resistência às formas modernas de escravidão, a luta por direitos sociais.

Entre os espaços de resistência, subversão e representação, podemos selecionar a literatura e a música. Essas modalidades de produção cultural estiveram sempre ao lado dos grupos dominantes, mas, também, dos grupos caracterizados pelo atrevimento. Foram a literatura e as letras de música alguns dos grandes meios de resistência dos períodos autoritários, bem como permanecem sendo espaços selecionados para a subversão e produção de representações alternativas. Assim, a música pode ser selecionada como um dos espaços mais profícuos.

Em especial, por conta da afinidade pessoal e pela repercussão mundial, selecionamos a música pop internacional como campo de seleção do corpus de pesquisa. Esse estilo musical, espaço de produção musical popular, assim como os demais estilos musicais populares, é marcado pela proposição de letras que apresentam os mais diversos temas, tais como: amor, romances, traição, amizade, recuperação, crises existenciais, maternidade/paternidade, entre outros.

Principalmente no cenário mais recente da indústria musical - desde a popularização da internet e da utilização dos meios digitais para propagação de informações e produtos culturais -, que presencia e lida com crises financeiras e mercadológicas, bem como dificuldades e embargos políticos, temos a necessidade de expressão das opressões e repressões impostas aos grupos minoritários e marginalizados.

No contexto do pop internacional, a cantora Ariana Grande, por exemplo, subverteu a ordem religiosa de que Deus é um ser superior caracterizado pelo masculino, ao dizer que Deus é uma mulher, na faixa homônima (God is a woman). Na letra da música, a intérprete diz que pode ser todas as coisas que o rapaz a diz para não ser, bem como que ela continuará florescendo mesmo após ser atacada:

And I can be all the things you told me not to be When you try to come for me, I keep on flourishing And he see the universe when I'm in company It's all in me.

(GRANDE, 2018). ${ }^{4}$

4 "E eu posso ser todas as coisas que você me disse para não ser / Quando você tenta me atacar, continuo florescendo / e ele vê o universo quando está em minha companhia / está tudo em mim" (GRANDE, 2018, tradução nossa). 
Ao prometer que ele será abençoado, após se confessar, o sujeito da enunciação, ou melhor, a sujeita da enunciação discursiva no feminino, diz ao rapaz que passará a acreditar que Deus é uma mulher, mesmo que o sentimento combatido permaneça, após passarem a noite juntos. Na música, é perceptível o empoderamento da mulher por meio da posse de seu corpo e de sua sexualidade, aquela que sabe como gosta e como quer (I'm tellin' you the way I like it, how I want it)5.

Ademais, para além dessas questões, falar que Deus é uma mulher foge a todos os princípios religiosos cristãos, pois a matriz religiosa judaico-cristã prevê que a mulher seja subjugada ao homem e que essa teria sido a vontade do Criador, pois fez a primeira mulher, Eva, da costela de Adão, o primeiro homem. Essa relação de submissão das mulheres (Evas) aos homens (Adãos) só se sustenta, de fato, pela crença em um Deus homem. De modo diferente, caso Deus fosse mulher, as interpretações poderiam ser outras...

Em contraponto, mesmo antes de Ariana Grande, a cantora britânica Marina \& the Diamonds já cantava as regras de como ser uma destruidora de corações (How to be a heartbreaker), dentre elas: se divertir sempre, não se apegar, deixá-lo sempre querendo mais. Segundo a letra, se a garota seguir as regras, conseguirá conquistar o rapaz:

This is how to be a heartbreaker Boys they like a little danger We'll get him falling for a stranger A player, singing lo-lo-lo-love you.

(DIAMONDS, 2012). ${ }^{6}$

Ao ensinar às garotas a como se tornarem destruidoras de corações, a cantora empodera as mulheres, invertendo a ordem esperada para atitudes masculinas e femininas (BOURDIEU, 2018): de que os homens devem tomar a iniciativa nas relações enquanto que elas devem esperar por eles; de que apenas as garotas devem ser sentimentais enquanto que os homens devem ser jogadores, sempre conquistando as mulheres.

Outra cantora promissora e que vem se destacando no cenário do pop internacional é Dua Lipa. Atualmente, a inglesa está sendo conhecida por suas letras que, assim como Marina, trazem regras de superação. A faixa New rules, do álbum de estreia da cantora, se tornou single (faixa de divulgação comercial) e foi indicada a mais de cinco prêmios internacionais de música.

Na letra, são enumeradas três regras para a compreensão do falso amor do exnamorado e, consequentemente, para o término e a superação do relacionamento.

5 "Eu estou te dizendo o jeito que eu gosto, como eu gosto" (tradução nossa).

6 "Isso é como ser uma destruidora de corações / Garotos gostam de um pouco de perigo / Vamos fazêlo se apaixonar por uma desconhecida / Uma jogadora, cantando a-a-a-amo você" (DIAMONDS, 2012, tradução nossa). 
Não atenda ao telefone, não o deixe entrar e não seja sua amiga; caso contrário, haverá complicações e recaídas:

One: Don't pick up the phone

You know he's only calling 'cause he's drunk and alone

Two: Don't let him in

You'll have to kick him out again

Three: Don't be his friend

You know you're gonna wake up in his bed in the morning

And if you're under him, you ain't gettin' over him.

(LIPA, 2018). ${ }^{7}$

Em outra faixa do mesmo álbum, $I D G A F^{8}$, a cantora, já empoderada, diz que não precisa mais do amor do seu ex-namorado, que ele fez suas escolhas e que ela também escolheu, mas por retirá-lo de sua vida. Ela decide que, mesmo dizendo estar arrependido e tendo colocado a culpa na bebida, que ela não o quer mais e que também não se importa mais com ele.

\section{“Okay, ladies, now let's get in formation ('cause I slay)"}

Beyoncé Giselle Knowles-Carter é cantora, atriz e compositora, nascida no estado de Texas, nos Estados Unidos, em 1981. Passou a ser conhecida na indústria musical com o trio Destiny's Child, no ano de 1997, mas começando sua carreira solo apenas em 2003. Ao longo de sua carreira, tornou-se a cantora com a maior quantidade de premiações por seus álbuns e músicas.

Longe de discutir as questões da indústria musical, enquanto produto do poder econômico, do capitalismo e da massa consumidora, nosso artigo propõe a análise crítica do conteúdo feminista presente nas letras das músicas da cantora Beyoncé.

A artista texana é considerada um grande símbolo do empoderamento feminino por conta de suas letras de música (e clipes musicais) que tornam as mulheres, principalmente negras, protagonistas de suas vidas, donas de posses, de seus corpos, de seus destinos. A pesquisa de Tauani Oliveira e Monica Sousa (2016) mostra a relação de fãs brasileiras com Beyoncé por meio de suas músicas e clipes.

No artigo, percebemos que a cantora é muito mais do que apenas uma artista: representa liberdade, poder, inspiração. Segundo as pesquisadoras, mesmo com

7 "Um: Não atenda ao telefone / Você sabe que ele está ligando apenas porque está bêbado e solitário / Dois: Não o deixe entrar / Você terá que colocá-lo para fora novamente / Três: Não seja sua amiga / Você sabe que vai acordar na cama dele de manhã / E, se você estiver por baixo dele, não vai superá-lo" (LIPA, 2018, tradução nossa).

8 A sigla abrevia a frase, que contém um palavrão de cunho sexual, "I don't give a f*ck".

9 O título da seção remete a um verso da música de Beyoncé, Formation: "Okay, garotas, agora vamos entrar em formação (porque eu arraso)" (KNOWLES, 2016). 
dificuldades, por conta de a história da indústria cultural ser majoritariamente comandada por homens, cantoras como Beyoncé conseguem ser ouvidas.

Assim como Dua Lipa, Marina \& the Diamonds e Ariana Grande - entre tantas outras cantoras que empoderam mulheres -, a cantora Beyoncé, desde o início da carreira, já mostrava, mesmo que em menor tom, traços de feminismo, como, por exemplo, ao dizer, em Irreplaceable, que seu ex-namorado não deve mexer nas coisas dela, pois a ela pertencem.

Nessa música, de 2006, a cantora já se mostra uma mulher dona de suas posses, que comanda, ao invés de ser comandada. Também se mostra uma mulher que não se abala com as palavras negativas de seu ex-namorado, dizendo que ela é estúpida por perdê-lo. Finaliza a discussão, dizendo que ele não é insubstituível:

\author{
Standing in the front yard telling me \\ How I'm such a fool, talking about \\ How I'll never ever find a man like you \\ You got me twisted \\ [...] You must not know 'bout me \\ I can have another you by tomorrow \\ So don't you ever for a second get \\ To thinking you're irreplaceable. \\ (KNOWLES, 2006). ${ }^{10}$
}

Na letra da música, estão representadas duas imagens: a do homem que pensa ser o único, insubstituível, aquele que parece sustentar; e a da mulher que é dona das posses, que compra o carro, que descobre a traição do ex-namorado, decide terminar o relacionamento e deixa claro que não sofrerá por essa perda.

As faixas de ***Flawless $(2013 ; 2014)$ apresentam uma mulher dona de si, com autoestima e amor próprio, que conquista seus objetivos e metas, que é empoderada e independente. Definitivamente, uma mulher feminista, que entende seu lugar na sociedade, que desvincula sua imagem à do marido e que galga melhorias para sua vida, sobretudo, para a sua emancipação pessoal.

Na faixa principal de 2013, a música tem a participação da escritora nigeriana e feminista negra Chimamanda Ngozi Adichie, que discursa, dentre outras coisas, sobre o homem que se sente ameaçado por mulheres, que detêm o poder, bem como sobre a reprodução do matrimônio como destino para todas as mulheres:

10 "Parado na frente do jardim me dizendo / como sou uma idiota, falando sobre / como eu nunca encontrarei um homem como ele / Você me deixou confusa / [...] você não deve saber nada sobre mim / Eu posso ter um outro igual a você amanhã/ então jamais, mesmo por um segundo, se pegue / pensando que você é insubstituível" (KNOWLES, 2006, tradução nossa). 
We teach girls to shrink themselves, to make themselves smaller We say to girls: You can have ambition, but not too much You should aim to be successful, but not too successful Otherwise, you will threaten the man

Because I am female, I am expected to aspire to marriage I am expected to make my life choices

Always keeping in mind that marriage is the most important

Now, marriage can be a source of joy and love and mutual support But why do we teach girls to aspire to marriage

And we don't teach boys the same?

We raise girls to see each other as competitors

Not for jobs or for accomplishments, which I think can be a good thing

But for the attention of men

We teach girls that they cannot be sexual beings in the way that boys are

Feminist: a person who believes in the social, political And economic equality of the sexes.

(KNOWLES; ADICHIE, 2013)."

Na letra da música, Adichie questiona a diferença da educação dada a meninos e meninas acerca do matrimônio, questiona "por que ensinamos às moças a quererem o casamento e não ensinamos o mesmo aos rapazes?” (tradução nossa). Ademais, fala ainda da criação dada às moças para que sejam vencedoras e, assim, conquistem rapazes, ao contrário do que se ensina às meninas que devem temer seu próprio corpo feminino, sua sexualidade, desejo e prazer.

Ao final do discurso, a escritora define uma pessoa feminista como em seu livro Sejamos todos feministas (2015, p. 49): "Feminista: uma pessoa que acredita na igualdade social, política e econômica entre os sexos". Aliás, toda a fala da autora, na música, coaduna com o discurso constante do livro supracitado.

Já, na faixa de 2014, com a participação da rapper Nicki Minaj, temos a construção de uma letra mais transgressiva, que aborda as duas artistas no topo das paradas de músicas e como são cobiçadas, por homens (sexualmente) e por mulheres (que buscam o mesmo poder), sendo elas o sonho e fantasias dessas pessoas.

\footnotetext{
11 "Nós ensinamos às garotas a se diminuírem, para serem ainda menores / Nós dizemos a elas: Você pode ter ambição, mas não demais / Você deve almejar ser bem-sucedida, mas não tanto / Do contrário, você ameaçará o homem / Porque eu sou do sexo feminino, esperam que eu anseie pelo casamento / Esperam que eu faça escolhas de vida / Sempre tendo em mente que o casamento é o mais importante / Agora, casamento pode ser uma fonte de alegria, amor e suporte mútuo / Mas por que ensinamos às moças a quererem o casamento / E não ensinamos o mesmo aos rapazes? / Nós criamos as moças para verem umas às outras como competidoras / Não por trabalhos ou conquistas, que eu penso que seria uma coisa boa / Mas pela atenção dos homens / Nós ensinamos às moças que elas não podem ser sexuais do mesmo jeito que os rapazes são / Feminista: uma pessoa que acredita na igualdade social, política e econômica entre os sexos" (KNOWLES; ADICHIE, 2013, tradução nossa).
} 
Por fim, para análise, a letra da música Formation, de 2016, que convoca a uma construção de identidade e representatividade negras. As pesquisadoras Oliveira e Sousa (2016, p. 11) dizem que "Ao lançar Formation ela [Beyoncé] declarou não apenas essas questões, também exaltou a representatividade negra”.

A letra de música retrata suas origens, tendo o pai de Alabama, a mãe de Louisiana e seu nascimento no Texas. Aqui, a cantora reafirma sua identidade sulista, mostrando-se uma mulher rebelde de berço, bem como a celebração de sua raiz negra: "My daddy Alabama, momma Louisiana / You mix that negro with that Creole, make a Texas bama" (KNOWLES, 2016) ${ }^{12}$.

Na oportunidade, a cantora ainda afirma o cabelo de sua filha, enquanto afro, bem como o gosto por ter um nariz marcadamente de pessoa negra, como os dos Jackson Five (banda de início da carreira de Michael Jackson): "I like my baby heir with baby hair and afros / I like my negro nose with Jackson Five nostrils"13.

Ao entrevistar as fãs brasileiras sobre a faixa, as pesquisadoras Oliveira e Sousa (2016, p. 11) perceberam que foram destacadas questões salutares presentes na letra de música Formation:

Dandara supõe "muitas pessoas embranqueceram a Beyoncé, e foi quando ela virou e falou "não gente, peraí, eu sou negra e eu sou "foda". E é isso, vocês aceitam, vocês aceitam e agora eu estou puxando todos os meus irmãos negros para serem "fodas" juntos comigo".

Como supôs Dandara, a cantora, em certo ponto da letra da música, faz um trocadilho sobre ser considerada como branca, mesmo sendo negra e bem aceita na indústria fonográfica. Por fim, a cantora convoca todas as moças/senhoras para entrarem em formação e arrasarem.

\section{Considerações finais}

Assim como Beyoncé - e as demais cantoras aqui apresentadas -, a artista nordestina, negra e feminista Doralyce, ao escrever a letra da música Miss beleza universal (epígrafe do artigo), discutiu as questões relacionadas ao imaginário de beleza padrão imposto às mulheres, pois não basta ser mulher, que é já uma ditadura e opressão, ainda é necessário estar enquadrada no padrão social aceitável de beleza. A música Pretty Hurts, de Beyoncé (KNOWLES, 2013), promove discussão similar, ao falar de aparência e adequação visual.

12 "Meu pai Alabama, mamãe Louisiana / Você mistura esse negro com o creoulo, faz uma Texana" (KNOWLES, 2016, tradução nossa).

13 "Eu gosto da minha filha com cabelo de bebê e afro / Eu gosto do meu nariz negro com narinas dos Jackson Five” (tradução nossa). 
Finalmente, a partir do estudo aqui realizado, foi possível perceber que existem questões feministas que precisam ainda ser mais bem discutidas, considerando as interseccionalidades entre categorias diversas da sociedade, como as questões de classe, profissão, raça, orientação sexual...

É necessário comentar, por fim, que existem outras vertentes importantes de feminismos que têm surgido e começam a ser discutidas, considerando outras formações e identificações possíveis, como é o caso do putafeminismo, que discute as questões das mulheres que se prostituem, e do transfeminismo, que propõe um feminismo pensado por e para as mulheres trans e travestis.

\section{Referências}

ADICHIE, Chimamanda Ngozi. (2015). Sejamos todos feministas. Tradução de Christina Baum. São Paulo: Companhia das Letras.

AMORÓS, Célia; ÁLVAREZ, Ana de Miguel. (2010). "Introdución: teoria feminista y movimientos feministas". In: (Eds.). Teoría feminista - de la Ilustración a la Globalización: de la Ilustración al segundo sexo, vol. 1. Madrid: Minerva Ediciones. p. $13-89$.

BEAUVOIR, Simone de. (2016a). O segundo sexo: fatos e mitos. 3. ed. Tradução de Sérgio Milliet. Rio de Janeiro: Nova Fronteira.

BEAUVOIR, Simone de. (2016b). O segundo sexo: a experiência vivida, volume 2. 3. ed. Tradução de Sérgio Milliet. Rio de Janeiro: Nova Fronteira.

BOURDIEU, Pierre. (2018). A dominação masculina. Tradução de Maria Helena Kühner. Rio de Janeiro: BestBolso.

DIAMONDS, Marina \& the. (2012). "How to be a heartbreaker". In: Electra heart. New York, US: Warner Music e Atlantic Records. Disponível em: <https://www. letras.mus.br/marina-and-the-diamonds/how-to-be-a-heartbreaker/>. Acesso em: 10 dez. 2018.

DORALYCE. (2017). "Miss beleza universal". In: Canto da revolução. [s./l.]: Doralyce. 1 CD. Faixa 6. Disponível em: <https://www.letras.mus.br/doralyce/missbeleza-universal/>. Acesso em: $10 \mathrm{dez} .2018$.

FERNANDES, Danubia de Andrade. (2016). "O gênero negro: apontamentos sobre gênero, feminismo e negritude”. Estudos Feministas. Florianópolis, 24 (3), p. 691713, set./dez. Disponível em: <https://periodicos.ufsc.br/index.php/ref/article/ view/46744/32490>. Acesso em: 18 abr. 2018. 
GRANDE, Ariana. (2018). "God is a woman". In: Sweetener. New York, US: Republic Records. 1 CD. Faixa 5. Disponível em: <https://www.letras.mus.br/arianagrande/god-is-a-woman/>. Acesso em: 10 dez. 2018.

JESUS, Jaqueline Gomes de. (2013). "Feminismo e identidade de gênero: elementos para a construção da teoria transfeminista”. In: Seminário Internacional Fazendo Gênero, v. 10, Florianópolis. p. 1-9. Disponível em: <http://www.fg2013. wwc2017.eventos.dype.com.br/resources/anais/20/1373329021_ARQUIVO_ FEMINISMOEIDENTIDADEDEGENERO.pdf>. Acesso em: 30 dez. 2018.

KNOWLES, Beyoncé. (2006). “Irreplaceable”. In: . B’Day. New York, US: Sony Music. 1 CD. Faixa 9. Disponível em: <https://www.letras.mus.br/beyonce/773281/>. Acesso em: 27 nov. 2018.

KNOWLES, Beyoncé. (2013). "Pretty hurts". In: Beyoncé. New York, US: Columbia Records. 1 CD. Faixa 1. Disponível em: <https://www.letras.mus.br/beyonce/ pretty-hurts>. Acesso em: 27 nov. 2018.

KNOWLES, Beyoncé. (2016). “Formation”. In: Lemonade. New York, US: Columbia Records. 1 CD. Faixa 12. Disponível em: <https://www.letras.mus.br/ beyonce/formation-dirty>. Acesso em: 27 nov. 2018.

KNOWLES, Beyoncé; ADICHIE, Chimamanda Ngozi. (2013). “***Flawless”. In: KNOWLES, Beyoncé. Beyoncé. New York, US: Columbia Records. 1 CD. Faixa 11. Disponível em: <https://www.letras.mus.br/beyonce/flawless/>. Acesso em: 27 nov. 2018.

KNOWLES, Beyoncé; MINAJ, Nicki. (2014). “***Flawless”. In: KNOWLES, Beyoncé. Beyoncé (Platinum Edition). New York, US: Parkwood Entertainment. 1 CD. Faixa 2. Disponível em: <https://www.letras.mus.br/beyonce/flawless-feat-nicki-minaj>. Acesso em: 27 nov. 2018.

LIPA, Dua. (2017). "IDGAF". In: Dua Lipa. New York, US: Warner Music. 1 CD. Faixa 5. Disponível em: <https://www.letras.mus.br/dua-lipa/idgaf/>. Acesso em: 10 dez. 2018.

LIPA, Dua. (2017). "New rules". In: Dua Lipa. New York, US: Warner Music. 1 CD. Faixa 10. Disponível em: <https://www.letras.mus.br/dua-lipa/new-rules/>. Acesso em: 10 dez. 2018.

MOIRA, Amara. (2016). E se eu fosse puta. São Paulo: Hoo. 
OLIVEIRA, Tauani Susi da Silva Marques de; SOUSA, Monica Christina Pereira de. (2016). "Feminismo, música e indústria cultural: um olhar sobre três singles da artista Beyoncé”. In: Congresso Brasileiro de Ciências da Comunicação, XXXIX. Anais... São Paulo, 5-9 set. p. 1-15. Disponível em: <http://portalintercom.org.br/anais/ nacional2016/resumos/R11-1520-1.pdf>. Acesso em: 27 nov. 2018.

OYÈWÚMI, Oyèronké. (200o). "Family bonds/conceptual binds: African notes on feminist epistemologies". Feminisms at a Millennium. Signs, v. 25, n. 4, The University of Chicago Press. p. 1093-1098. Disponível em: <http://www.jstor.org/stable/3175493>. Acesso em: 10 jan. 2019.

OYĚWÙMÍ, Oyèrónké. (2004). "Conceptualizing gender: the Eurocentric foundations of feminist concepts and the challenge of African epistemologies". African gender scholarship: concepts, methodologies and paradigms. CODESRIA Gender Series, v. 1, Dakar, CODESRIA. p. 1-5. Disponível em: <https://www.codesria.org/IMG/pdf/ OYEWUMI.pdf>. Acesso em: 10 jan. 2019.

PRADA, Monique. (2018). Putafeminista. Prefácio de Amara Moira. Apresentação de Adriana Piscitelli. São Paulo: Veneta.

PULEO, Alicia H. (2010). "Lo personal es político: el surgimiento del Feminismo Radical”. In: AMORÓS, Célia; ÁLVAREZ, Ana de Miguel (Eds.). Teoría feminista - de la Ilustración a la Globalización: del feminismo liberal a la posmodernidad, vol. 2. Madrid: Minerva Ediciones. p. 35-67.

RIBEIRO, Djamila. (2017). O que é: lugar de fala? Belo Horizonte: Letramento; Justificando.

SCHMIDT, Rita Terezinha. (2017). O projeto iluminista e os direitos da mulher. In: . Descentramentos/convergências: ensaios de crítica feminista. Porto Alegre:

Editora da UFRGS. p. 235-243.

SCOTT, Joan Walach. (2002). Relendo a História do Feminismo. In: A cidadã paradoxal: as feministas francesas e os direitos do homem. Tradução de Élvio Antônio Funck. Florianópolis: Mulheres. p. 23-48.

SPIVAK, Gayatri Chakravorty. (1994). Can the subaltern speak? In: WILLIAMS, Patrick; CHRISMAN, Laura (Eds.). Colonial discourse and post-colonial theory: a reader. New York: Columbia University Press. p. 66-111. 